\title{
The influence of selected factors on the perceptions of managers of medium business firms regarding legal firms
}

\author{
M. Tait* \\ Department of Business Management, University of Port Elizabeth, P.O. Box 1600. Port Elizabeth, 6000 South Africa \\ ecammt@upc.ac.za \\ M. Tait \\ Department of Public Law, Vista University, Private Bag X613. Port Elizabeth, 6000 South Africa \\ tait-am@pelican.vista.ac.za
}

S.M. van Eeden

Department of Business Management, University of Port Elizabeth, P.O. Box 1600, Port Elizabeth, 6000 South Africa ecasve@upe.ac.za

Received August 2000

\begin{abstract}
The South African service provider is faced with an increasingly turbulent and complex competitive environment. Factors which impact specifically on the environment of service firms include the growing importance of consumerism and a drastic increase in competition. A factor that impacts directly on the growing competition amongst providers of legal services is the increase in law graduates and commensurate increase in qualified attorneys and advocates entering the market. This article represents an exploratory study establishing the relative value attached by medium business in South Africa to certain factors pertaining to firms providing legal services.
\end{abstract}

* Author to whom correspondence should be addressed.

\section{Introduction}

Firms cannot survive on their own, in other words completely isolated, because firms are part of the environments within which they function. Firms receive inputs such as the factors of production from the external environment and deliver outputs to the environment. Enterprises are exposed to changes in these environments. These changing environments may have positive or negative consequences for enterprises. Various interactive forces (environmental variables) affect the environment of enterprises. This creates certain opportunities or threats for firms (Marx, Van Rooyen, Bosch \& Reynders, 1998: 37).

The South African service provider is thus faced with an increasingly turbulent and complex competitive environment (Griffith \& Rust, 1997: 109-116). Factors which impact specifically on the environment of service firms (such as the providers of legal services) include the growing importance of consumerism and a drastic increase in competition (Harrel \& Fors, 1992: 299-306; Kahn, 1998: 45-53).

The latter factor has a number of causes including, amongst others, a stagnating economy (Griffith \& Rust, 1997: 109116). A factor that impacts directly on the growing competition amongst providers of legal services is the increase in law graduates and commensurate increase in qualified attorneys and advocates entering the market.

Figures supplied by the Law Society of the Cape of Good Hope and the Law Society of the Transvaal indicate an increase in excess of $50 \%$ in the number of practising attorneys in both the former provinces of the Cape and Transvaal between the years 1990 and 1997. In the former Cape Province (including the former Ciskei and Transkei) there were 2027 practising attorneys in 1990. This figure increased to 3173 in 1997 , amounting to an increase of $56.5 \%$. In the former Transvaal there were 3632 practising attomeys in 1990 . This figure increased by $54.7 \%$ to a total of 5621 in 1997. These figures represent a drastic increase in the number of providers of legal services, specifically as far as attomeys are concerned.

\section{Objectives and problem investigated}

In order for a firm to survive and prosper in an environment as indicated above, the firm must adopt a marketingorientated strategy. This means that responsiveness to customer needs should be the central focus of all marketing activities (Lamb, Hair \& McDaniel, 1998: 833; Menon, Jaworski \& Kohli, 1997: 187-200; Ramsey \& Sohi, 1997: 127-137).

Historically, customer service has been seen from a somewhat narrow perspective. This narrow perspective suggests that the primary role of customer service is concerned with getting the right product to the right place at the right time and the focus was primarily from a distribution and logistics viewpoint. However, a new vision of customer service has started to emerge (Christopher, Payne \& Ballantyne, 1993: 5).

In essence one has to listen to one's clients and potential clients and build a relationship with them (Duhan, Johnson, Wilcox \& Harrell, 1997: 283). In the case of a firm providing a service, it may be even more important to know what the perceptions are of one's firm as opposed to a firm providing a physical product. In the latter situation the customer may be more interested in the physical product as an entity separate from the producer or provider of the product, whilst in the 
case of a service provider, the provider is seen as synonymous with the product (service).

Consumers apply various decision strategies in their information processing tasks because they cannot process all of the information that is available for purchase decisions (Duhan et al., 1997: 283). These decision strategies can be divided on the one hand into processes whereby the consumer processes information on both product alternatives and their attributes, without the assistance of others. Factors such as location, personal knowledge. knowledge of the service and perception of the service, may be relevant information in the decision process of a client in deciding on support for a particular provider of legal services. On the other hand there are processes whereby the consumer makes use of the assistance of people to help him or her in his or her decision, for example by means of word-of-mouth and advertising. The perceptions of a firm may be influenced by a host of factors, inter alia the factors mentioned above. Clearly, positive perceptions about a firm (and the service it renders) will determine support and loyalty for such a firm.

This article considers a selected number of factors in order to determine their impact on the perceptions held by managers of medium business firms regarding legal firms. These factors are advertising, word-of-mouth, personal knowledge. knowledge of the service. location and perceptions of the service.

For the purposes of this article the factor personal knowledge is understood to mean that the respondents personally know member(s) of legal firms, who may be friends or family for example, whilst knowledge of the service is understood to mean the actual knowledge the respondent has in respect of the service provided by a specific legal firm.

\section{Research objectives}

The primary objective of this research is to establish the value attached by current and potential clients from a medium business firm market segment to certain factors pertaining to firms providing legal services. Once this has been established it will be possible to advise these firms as to the relevant importance of these various factors facilitating, hopefully, more effective strategising as well as better service delivery to clients.

A secondary objective is the design (and testing) of a measuring instrument for use in future research of this nature. The factor analysis done on the collected data will assist in establishing the relative worth of the different individual measuring items used in the measuring instrument.

\section{Methodology \\ Sample selection}

The focus of the article is managers of medium firms and judgmental sampling was used. The sample size was 230 , which yielded 126 useable questionnaires. The response rate of $54.78 \%$ was regarded as acceptable.

Questionnaires were mailed to each respondent's work address with a reply-paid envelope and covering letter. Completed questionnaires were mailed back directly to the researchers.

\section{Measuring instrument}

The measuring instrument used for this specific study, consisting of 39 items, was developed and used by the researchers in a similar study.

\section{Data analysis and empirical findings}

A stepwise reliability analysis was performed by using SAS PROC CORR (SAS Institute. Inc. 1990). In this stepwise analysis individual measurements of a measuring instrument are removed if such deletion will result in an improvement of the internal consistency (as measured by Cronbach's alpha coefficient). The procedure terminates when the alpha coefficient of the measuring instrument can no longer be improved by deleting individual measurements.

For the purpose of this study the recommended cut-off value of 0.7 , as suggested by Nunnaly (1978), was used to indicate significance of the individual measuring instruments.

After a Cronbach alpha analysis was conducted it became evident that certain items had to be removed from further analysis to obtain higher Cronbach alpha values for the different factors. These items included those for word-of-mouth and knowledge of the service (see Table 1).

\section{Table 1 Final instruments}

\begin{tabular}{lc}
\hline Variables & Alpha coefficients \\
\hline Advertising & 0.887 \\
Word-of-mouth & 0.659 \\
Personal knowledge & 0.920 \\
Location & 0.914 \\
Knowledge of service & 0.619 \\
Perceptions of service & 0.916 \\
\hline
\end{tabular}

The discriminant and construct validity of the instruments were assessed by means of a stepwise exploratory factor analysis. In the application of this procedure individual measurements are removed from measuring instruments if this action yields an instrument with an acceptable level of validity. In each step of this analysis, a maximum likelihood factor analysis with a Direct Quartimin oblique rotation of the original factor matrix was performed by using the computer program BMDP4M (Frane, Jennrich \& Solomon, 1990: 331-337). The rotated factor loadings of the final set of adapted measuring instruments are listed in Table 2.

From the results reflected in Table 2 it can be deduced that from the selected factors advertising, personal knowledge, location and perception of the service yielded instruments with acceptable levels of validity.

Mean values for the different variables were identified. Table 3 ranks the variables in order of importance according to their mean values.

The mean values indicate that perception of the service rated the highest amongst respondents and advertising the lowest.

\section{Implications for management}

Continuous environmental scanning is necessary for strategy formulation. When the capability of the enterprise is syn- 
Table 2 Rotated factor loadings (final step)

\begin{tabular}{lcccc}
\hline Variable & Factor 1 & Factor 2 & Factor 3 & Factor 4 \\
\hline Advert 6 & -0.021 & $\mathbf{0 . 9 6 4}$ & 0.002 & 0.011 \\
Adven 7 & 0.132 & $\mathbf{0 . 8 7 9}$ & -0.032 & -0.023 \\
Advert 8 & -0.045 & $\mathbf{0 . 8 9 0}$ & 0.057 & 0.031 \\
Advert 10 & -0.016 & $\mathbf{0 . 8 3 5}$ & 0.014 & 0.004 \\
Perknow1 & 0.132 & 0.055 & $\mathbf{0 . 6 9 5}$ & 0.120 \\
Perknow2 & 0.074 & 0.050 & $\mathbf{0 . 8 2 1}$ & 0.016 \\
Perknow3 & -0.050 & 0.047 & 0.951 & 0.014 \\
Perknow4 & 0.011 & -0.060 & $\mathbf{0 . 9 8 1}$ & -0.013 \\
Locate 1 & $\mathbf{0 . 6 4 9}$ & 0.126 & 0.054 & 0.102 \\
Locate2 & $\mathbf{0 . 8 6 0}$ & 0.007 & 0.104 & -0.160 \\
Locate3 & $\mathbf{0 . 9 2 4}$ & 0.015 & -0.010 & -0.0147 \\
Locate4 & $\mathbf{0 . 7 3 1}$ & 0.062 & 0.036 & 0.009 \\
Locate5 & $\mathbf{0 . 6 6 3}$ & -0.055 & -0.048 & 0.293 \\
Locate6 & $\mathbf{0 . 6 0 2}$ & 0.105 & 0.078 & 0.101 \\
Locate7 & $\mathbf{0 . 6 3 0}$ & 0.006 & 0.070 & 0.146 \\
Percep3 & -0.018 & -0.032 & 0.128 & $\mathbf{0 . 8 6 5}$ \\
Percep4 & 0.098 & 0.195 & -0.024 & $\mathbf{0 . 6 6 3}$ \\
Percep5 & 0.088 & 0.025 & 0.093 & $\mathbf{0 . 7 7 9}$ \\
\hline
\end{tabular}

Table 3 Mean values

\begin{tabular}{ll}
\hline Variable & Mean \\
\hline Perception of service & 5.765 \\
Personal knowledge & 4.567 \\
Location & 4.368 \\
Advertising & 3.430 \\
\hline
\end{tabular}

chronised with opportunities in the business environment, it provides a better understanding of the role of the enterprise in society and constant awareness enables management to overcome threats from a changing environment timeously and to exploit opportunities meaningfully.

Apart from the above, various other aspects for consideration by the manager of a service providing firm, are revealed by the research.

The mean values indicated that the respondents regarded perception of the service as being the most important factor (as compared to the other factors) when they chose a legal firm with whom to do business.

The research affirms that personal knowledge and contact with a service provider, such as a firm of attorneys, is a significant factor in determining perceptions of clients of service providers.

The location of a firm of attorneys is also a consideration for a manager of a medium business firm. If, for example, a legal firm is located in a so-called 'good area' managers of medium business firms will perceive such a legal firm positively.

Interestingly, firms of attorneys that advertise will be perzeived less positively by managers of medium business firms.

\section{References}

Berry. L.L. 1990. Big ideas in services marketing, The Journal of Consumer Marketing, 2(3): 29-38.

Christopher, M., Payne, A. \& Ballantyne, D. 1993. Relationship marketing. Oxford: Butterworth-Heinemann Ltd, 204p.

Duhan. D.G.. Johnson, S.D., Wilcox, J.B. \& Harrell, G.D. 1997. Influences on consumer use of word-of-mouth recommendation sources. Journal of the Academy of Marketing Science. 25(4): 283-295.

Frane, J., Jennrich, R.I. \& Solomon, P.F. 1990. F4M factor analysis In Dixon, W.J. \& Brown, M.B. Eds. BMDP Statistical Software Manual: Volume I. Berkeley: University of California, pp. 311337.

Griffith, D.E. \& Rust, R.T. 1997. The price of competitiveness in competitive pricing, Journal of the Academy of Marketing Science, 25(2): 109-116.

Harrell, G.D. \& Fors, M.F. 1992. Internal marketing of a service, Industrial Marketing Management, 21: 299-306.

Kahn, B.E. 1998. Dynamic relationships with customers: high-variety strategies, Journal of Academy of Marketing Science, 26(1): 45-53.

Lamb, C.W., Hair, J.F. \& McDaniel, C. 1998. Marketing. Cincinnati. Ohio: South Western, 693p.

Marx, S., Van Rooyen, D.C., Bosch, J.K. \& Reynders, H.J.J. Eds. 1998. Business management. $2^{\text {nd }}$ Ed. Pretoria: J.L. Van Schaik, $797 \mathrm{p}$.

Menon, A., Jaworski, B.J. \& Kohli, A.K. 1997. Product quality: impact of interdepartmental interactions. Journal of the Academy of Marketing Science, 25(3): 187-200.

Nunnaly, J. 1978. Psychometric theory. $2^{\text {nd }}$ Ed. New York: McGrawHill.

Ramsey, R.P. \& Sohi, R.S. 1997. Listening to your customers: the impact of perceived salesperson listening behaviour on relationship outcomes, Journal of the Academy of Marketing Science, 52 (2): $127-137$

SAS Institute Inc. 1990. SAS Procedures. (Release 6.03 Ed.) Cary. N.C.: Author. 


\section{Annexure A}

\section{Evaluate your attorney or firm of attorneys}

Instructions: The following statements refer to your perceptions as a professional person regarding your attorney or firm of attomeys. Please show the extent to which you think your attorney or firm of attorneys possesses the features described by each statement. Do you strongly agree that your attorney or firm of attorneys possesses a feature, circle the number 7 . If your feelings are not particularly strong, circle 4 . There are no right or wrong answers - you must merely indicate a number that best reflects your perceptions about your attorney or firm of attorneys. Thank you

I Firms of attorneys which make use of advertising are more professional than firms which do not

2 Firms of attorneys make use of advertising because they have struggled to get sufficient business in the past

3 I will make use of an attorneys firm because the firm uses advertising

4 If I have to choose between two firms of attorneys. I would choose the one making use of advertising

5 Firms of attorneys make use of advertising because they want to improve their image

6 The fees charged by tirms of attorneys, which make use of advertising, are higher than fees of firms which do not use advertising

7 I believe that firms of attorneys, which make use of advertising, will provide a better service

8 Today all firms of attorneys should make use of advertising

9 Firms of attorneys, which do not make use of advertising. do not need to advertise

10 Firms of attorneys which make use of advertising, are more modern and up to date than those which do not use advertising

11 I do business with my current firm of attorneys because they were recommended to me by family/friends/business acquaintances

12 I will leave my current firm of attorncys if I hear that my family/friends/business acquaintances had an unpleasant experience with them

13 I will rather go to a firm of attorneys which my family/friends/business acquaintances recommend. than to one which became known to me by means of advertising

14 It is important to me to know that a firm of attorneys was well accepted by my family/ friends/business acquaintances. before I wili consider such a firm

15 The more people talk about a firm of attorneys, the more successful such a firm is

16 I always choose my firm of attorneys according to the nature of a problem or situation

17 I will (without being unhappy with my current firm of attorneys) move to another firm of attorneys if I perceive them to render a better service

18 I will move to another firm of attorneys if I perceive the fees of my current firm of attorneys as being too high

19 I am with my current firm of attorneys, because of my personal experience of knowledge regarding their good service

20 Knowledge I have regarding the unethical rendering of service by my current firm of attorneys in respect of others does not influence my relationship with my firm of attorneys

21 I support the firm of attorneys where my family/friends/business acquaintances practice

22 I am loyal to my family/friends/business acquaintances that are attorneys. and will not support their competitors

23 I prefer a professional relationship w ith the firm of attorneys which $m$ ! business and I usc, rather than to make use of a family member or a friend who is an attorney

24 I will use a firm of attorne's that was 'against' me in the past. but who impressed me with their service and/or conduct

25 I am with my current firm of attorneys because of the fact that one or more of the attorneys is/are my personal friend(s)

26 The attorney of my business is also my personal attorney

\begin{tabular}{|c|c|c|c|c|c|}
\hline \multicolumn{2}{|c|}{ Agree strongly } & \multicolumn{3}{|c|}{ Neutral } & Disagree \\
\hline 7 & 6 & 5 & 4 & 3 & 2 \\
\hline 7 & 6 & 5 & 4 & 3 & 2 \\
\hline 7 & 6 & 5 & 4 & 3 & 2 \\
\hline 7 & 6 & 5 & 4 & 3 & 2 \\
\hline 7 & 6 & 5 & 4 & 3 & 2 \\
\hline 7 & 6 & 5 & 4 & 3 & 2 \\
\hline 7 & 6 & 5 & 4 & 3 & 2 \\
\hline 7 & 6 & 5 & 4 & 3 & 2 \\
\hline 7 & 6 & 5 & 4 & 3 & 2 \\
\hline 7 & 6 & 5 & 4 & 3 & 2 \\
\hline 7 & 6 & 5 & 4 & 3 & 2 \\
\hline 7 & 6 & 5 & 4 & 3 & 2 \\
\hline 7 & 6 & 5 & 4 & 3 & 2 \\
\hline 7 & 6 & 5 & 4 & 3 & 2 \\
\hline 7 & 6 & 5 & 4 & 3 & 2 \\
\hline 7 & 6 & 5 & 4 & 3 & 2 \\
\hline 7 & 6 & 5 & 4 & 3 & 2 \\
\hline 7 & 6 & 5 & 4 & 3 & 2 \\
\hline 7 & 6 & 5 & 4 & 3 & 2 \\
\hline 7 & 6 & 5 & 4 & 3 & 2 \\
\hline 7 & 6 & 5 & 4 & 3 & 2 \\
\hline 7 & 6 & 5 & 4 & 3 & 2 \\
\hline 7 & 6 & 5 & 4 & 3 & 2 \\
\hline 7 & 6 & 5 & 4 & 3 & 2 \\
\hline 7 & 6 & 5 & 4 & 3 & 2 \\
\hline 7 & 6 & 5 & 4 & 3 & 2 \\
\hline
\end{tabular}


27 I prefer firms of attorneys which are situated close to where I live

28 I prefer firms of attorneys which are situated close to where I work

29 Firms of attorneys should be situated within the central business district

30 The location of firms of attorneys is a very important factor to me when I have to choose an attorney

31 If I have to choose between two firms of attorneys, I will choose the one that is situated in a 'better' part of the city (e.g. Newton Park versus North End)

32 The location of firms of attorneys is definitely an indication of the prestige of the firm

33 The location of a firm of attorneys determines the clients of the firm

34 The clients of a firm of attorneys determine the location of the firm

35 My personal information and the information of my firm are always treated confidentially by my firm of attorneys

36 I am of the opinion that my firm of attorneys is always ethical in their behaviour towards me

37 My firm of attorneys always treats me and my firm professionally

38 My firm of attorneys engenders my trust as a result of the manner in which they handle my personal matters

39 I am of the opinion that the fees charged by my firm of attorneys are always reasonable and fair

\begin{tabular}{ccccccc}
\multicolumn{2}{c}{ Agree strongly } & \multicolumn{3}{c}{ Neutral } & \multicolumn{2}{c}{ Disagree } \\
7 & 6 & 5 & 4 & 3 & 2 & 1 \\
7 & 6 & 5 & 4 & 3 & 2 & 1 \\
7 & 6 & 5 & 4 & 3 & 2 & 1 \\
7 & 6 & 5 & 4 & 3 & 2 & 1 \\
7 & 6 & 5 & 4 & 3 & 2 & 1 \\
7 & 6 & 5 & 4 & 3 & 2 & 1 \\
7 & 6 & 5 & 4 & 3 & 2 & 1 \\
7 & 6 & 5 & 4 & 3 & 2 & 1 \\
7 & 6 & 5 & 4 & 3 & 2 & 1 \\
7 & 6 & 5 & 4 & 3 & 2 & 1 \\
7 & 6 & 5 & 4 & 3 & 2 & 1 \\
7 & 6 & 5 & 4 & 3 & 2 & 1 \\
7 & 6 & 5 & 4 & 3 & 2 & 1
\end{tabular}

